\title{
Reflexiones sobre la educación en tiempos de COVID-19: retos y perspectivas
}

\author{
Reflections on Education in Times of COVID-19: Challenges and Perspectives
}

\author{
Ernesto Cotonieto-Martínez'; Ramón Martínez-García²; Rodrigo Rodríguez-Terán ${ }^{3}$
}

\begin{abstract}
RESUMEN
La pandemia por COVID-19 y la declaración de emergencia sanitaria nacional en México modificaron la organización de las instituciones nacionales en todos los ámbitos, incluyendo el educativo. Se implementaron medidas de distanciamiento social para prevenir y mitigar la transmisión del virus, lo que implicó la adopción de ambientes virtuales de aprendizaje para continuar con el proceso de enseñanza-aprendizaje. El presente texto reflexiona en torno a los principales retos del aprendizaje en línea y a distancia durante la pandemia, y cómo esta experiencia puede ser aprovechada para fortalecer habilidades sociales y el dominio de tecnologías que deberían ser consideradas para enriquecer el proceso enseñanza-aprendizaje, sobre todo considerando que condiciones similares puedan darse en el futuro.
\end{abstract}

Palabras claves: educación en línea; educación a distancia; pandemia; COVID-19; tecnología educativa; TIC.

\begin{abstract}
The COVID-19 pandemic and the declaration of national health emergency in Mexico modified the organization of national institutions in all areas, including education. Social distancing strategies were implemented to prevent and mitigate the virus transmission, and that implied choosing virtual learning environments to continue the teaching-learning process. This text reflects on main challenges of e-learning during quarantine, and how this experience can be used to strengthen social skills and mastery of technologies that should be considered to enrich the teaching-learning process, especially considering that similar conditions may occur in the future.
\end{abstract}

Keywords: Online education; long distance education; pandemic; COVID-19; educative technology; ICT.

\footnotetext{
${ }^{1}$ Docente y director de la Unidad de Atención Psicológica Integral (UAPI), Teotihuacán, México; Maestro en Ciencias Biomédicas y de la Salud, Universidad Privada del Estado de México, Teotihuacán, México; cotonietoe@gmail.com.

${ }^{2}$ Estudiante de Licenciatura en Psicopedagogía, Universidad Privada del Estado de México, Teotihuacán, México; rmartinezgarcia556@gmail.com.

${ }^{3}$ Estudiante de Licenciatura en Psicología, Universidad Privada del Estado de México, Teotihuacán, México.
} 


\section{Introducción}

A lo largo de la historia, la humanidad se ha enfrentado a diversas crisis humanitarias que han marcado un punto de quiebre en la estructura y organización social. Sin embargo, la emergencia sanitaria ocasionada por el COVID-19 es un acontecimiento sin precedentes, que ha puesto a prueba nuestras capacidades de afrontamiento como sociedad, obligándonos a modificar diversas prácticas en ámbitos como el sanitario, político, económico y educativo, entre otros.

El impacto de la pandemia en el sector educativo es extremadamente complejo. Tanto es así que, de acuerdo con la Organización de las Naciones Unidas (ONU, 2020a), los efectos en el corto y largo plazo podrían implicar un retroceso en los avances alcanzados durante las últimas décadas para la educación de niños, niñas, adolescentes y jóvenes, especialmente en poblaciones bajo condiciones de vulnerabilidad.

Recordemos que, como parte de las medidas de seguridad para mitigar la propagación del virus SARS-CoV-2, se procedió al cierre de centros educativos públicos y privados, lo que desembocó en la posterior implementación de estrategias alternativas de enseñanza para dar continuidad al proceso de enseñanza-aprendizaje. En consecuencia, esta afectación a las actividades académicas usuales ha puesto en riesgo el derecho de acceso a la educación en diversos países (Fondo de las Naciones Unidas para la Infancia [Unicef], 2020a). De hecho, según proyecciones realizadas por la ONU (2020b), cerca de mil millones de estudiantes verán interrumpidos sus estudios en el mundo. En el caso de México, aproximadamente 1.4 millones podrían abandonar las clases y no regresar al ciclo 2020-2021, siendo la adopción de estrategias para el aprendizaje en línea y a distancia uno de los factores asociados a estas proyecciones.

Con base en lo anterior, el presente texto tiene como objetivo poner sobre la mesa los principales retos que nos plantea el aprendizaje en línea y a distancia durante la cuarentena por COVID-19, e identificar la forma en que la experiencia puede ser aprovechada para el fortalecimiento de condiciones que permitan hacer frente a la actual y futuras realidades educativas derivadas de este contexto. 


\section{Retos del aprendizaje en línea y a distancia durante la cuarentena}

La educación en México, como en otros países de Latinoamérica, ya enfrentaba graves problemas respecto a su calidad y distribución equitativa, previo al inicio de la pandemia (Instituto Nacional de la Evaluación de la Educación [INEE], 2018). A pesar de las diversas reformas educativas puestas en marcha en los últimos años, el vertiginoso crecimiento de la sociedad del conocimiento y el abrumador avance e innovación de las tecnologías acentuaron la brecha de desigualdades preexistentes, impidiendo el acceso, permanencia y conclusión de la educación (INEE, 2019).

Considerando que la educación de calidad para el aprendizaje útil, relevante y significativo depende de la capacidad del sistema educativo para adaptarse a los retos emergentes, mecanismos de organización, materiales y métodos educativos, así como del desempeño de los diversos actores involucrados y la infraestructura (INEE, 2019), diversas acciones han enfatizado la necesidad de mejorar las condiciones de infraestructura tecnológica para la formación continua y de alta calidad, especialmente en escuelas en contextos rurales y urbanos marginales (INEE, 2018).

Sin embargo, este impulso ha estado desfasado y la brecha podría extenderse con la implementación de estrategias educativas vía internet y a distancia que no son congruentes con la infraestructura tecnológica disponible o que no consideran las condiciones aplicables a cada sector de la población, dentro del contexto pandémico actual. Al respecto, una investigación realizada recientemente por Unicef (2020b) encontró que el 73\% de los 127 países que formaron parte de ese estudio están utilizando plataformas en línea para dar continuidad a los servicios educativos, en tanto que en América Latina y el Caribe la cifra se incrementa al 90\%. No obstante, para que este tipo de estrategias sean efectivas, se necesita que se cumplan al menos dos supuestos: contar con una computadora en casa y tener acceso a internet. Teniendo en cuenta que en México solo el $60 \%$ cumple con lo segundo, se vuelve una alternativa excluyente y poco realista para un gran número de estudiantes y docentes (ONU, 2020c). 
Lo anterior tiene que ver con que, ante la necesidad de acciones rápidas, se toman decisiones que no consideran las diversas realidades de la población. Por ejemplo, de acuerdo con los datos de la Encuesta Nacional de Disponibilidad y Uso de Tecnologías de la Información en Hogares (ENDUTIH), el 52,3\% de la población mexicana vive en zonas rurales sin acceso a internet y el 55,7\% forma parte de familias con ingresos insuficientes para adquirir algún dispositivo de cómputo o, incluso, para atender las necesidades más básicas (Instituto Nacional de Estadística y Geografía, 2020). En consecuencia, la brecha digital representa una enorme barrera que impide, o dificulta en el mejor de los casos, el goce del derecho a la educación (Unicef, 2020c).

Aun quienes poseen acceso a estos recursos se enfrentan a otro reto: la apropiación de la tecnología para conseguir un dominio lo suficientemente amplio de las herramientas digitales, que les permita utilizarlas para la adquisición de conocimientos. En este sentido, el sistema educativo mexicano no ha sido capaz de incorporar de manera adecuada programas para el apoyo, capacitación y optimización de las habilidades tecnológicas de docentes y estudiantes. Esto se debe, en parte, a que las acciones emprendidas no se han basado en diagnósticos integrales que mejoren la toma de decisiones en este campo (Azamar, 2016). Además, tomar clases bajo la modalidad virtual exige una gran capacidad para ajustarse a nuevas demandas académicas, propias de los ambientes virtuales, para la realización de diferentes actividades. Lo anterior, de acuerdo con Kriscautzky y Rodríguez (2018), implica contar con habilidades y herramientas para lograr un manejo básico de las tecnologías de información y comunicación (TIC), obtener y evaluar información de distinta índole, usar éticamente la información para crear contenidos nuevos y desarrollar una identidad y ciudadanía digitales.

La ausencia de este tipo de habilidades y competencias, tanto en docentes como en estudiantes, no solamente tiene el potencial de entorpecer el logro de los objetivos de enseñanza-aprendizaje, sino que también podría incrementar la brecha de acceso a servicios educativos de calidad, más allá de la condición socioeconómica. Este riesgo es aún mayor para la educación en los niveles básicos, como la primaria y secundaria, puesto que las 
personas cuidadoras también suelen carecer de estas competencias tecnológicas y podrían verse rebasadas por las exigencias del nuevo contexto educativo.

Ahora bien, aparte del rezago en el dominio de la tecnología, existe otro reto sumamente importante, el cual tiene que ver con el fomento de las habilidades sociales. Estas últimas son necesarias para el establecimiento de nuevos y mejores mecanismos de comunicación que permitan el intercambio efectivo de información entre las personas incluidas en los entornos virtuales seleccionados (según las actividades, objetivos y características de la audiencia). Asimismo, son claves para una comunicación efectiva, que contribuya al logro de resultados satisfactorios de aprendizaje mediante el trabajo colaborativo (Villasana y Dorrego, 2007).

De igual manera, las habilidades sociales son fundamentales para la sana interacción de los actores del proceso enseñanza-aprendizaje, fuera de los ambientes virtuales, y dicha interacción impacta en la educación. Por ejemplo, los patrones de comunicación transmitidos por los/as cuidadores/as y la relación que tienen con los/as estudiantes, determinarán el tipo de ajuste social y los vínculos a desarrollar ante pares y docentes, lo que a su vez impacta en el aprendizaje y rendimiento académico (Romagnoli y Cortese, 2016).

Sin embargo, de acuerdo con la Comisión Nacional de los Derechos Humanos (2020), el aislamiento de las personas en sus hogares, las dificultades financieras, el estrés y las posibles crisis emocionales debidas a la contingencia sanitaria, incrementan el riesgo de conflictos entre los miembros del hogar, pudiendo esto derivar en maltrato, abuso o violencia de algún tipo, especialmente por parte de los/as cuidadores/as que tienen que trabajar desde casa, encargarse de actividades propias del hogar y orientar el aprendizaje de sus hijos e hijas, todo al mismo tiempo.

Al respecto, es importante señalar las dificultades que ciertos estilos de crianza pueden generar en los y las estudiantes. Por ejemplo, el control patológico y la negligencia parental son predictores de peores estrategias de aprendizaje autorregulado y mayor sintomatología ansiosa ante exámenes. En cambio, los estilos de crianza democráticos, caracterizados por afecto, compromiso y aceptación, predicen motivación, responsabilidad, administración 
adecuada del tiempo, técnicas de ayuda al estudio y autoevaluación para un mejor desempeño académico (Malander, 2016).

En este punto, vale la pena destacar la paciencia como una cualidad relacionada con las prácticas parentales, que implica un uso adecuado de habilidades de autorregulación emocional ante situaciones de estrés y tensión (Organización Panamericana de la Salud y Unicef, 2020). Por ejemplo, pensemos en los momentos en que los/as estudiantes tienen problemas para la elaboración de las actividades académicas y buscan apoyo (instrumental o afectivo), pero se enfrentan a actitudes de indiferencia, recriminación e, incluso, violencia por parte de sus tutores/as, lo que sin duda impacta de manera negativa en su motivación.

Sumado a lo anterior, la motivación también puede verse disminuida por el hecho de cambiar desde una modalidad de estudio presencial a otra de trabajo en línea y a distancia, independientemente del nivel educativo, convirtiéndose en un factor de riesgo para la deserción escolar y un pobre desempeño académico (Mateo, 2020). Por esta razón, se requiere buscar estrategias de acompañamiento que promuevan el fortalecimiento de habilidades de organización, autonomía y participación, que permitan incrementar la motivación y la capacidad de autorregulación para el aprendizaje (Unicef, 2020d).

Es importante señalar que, además de las competencias tecnológicas, el uso de estrategias de aprendizaje adecuadas y el dominio de estrategias pedagógicas efectivas, deben tomarse medidas de prevención ante problemáticas emocionales y conductuales asociadas a la nueva realidad de la educación en línea (Unicef, 2020e). El deterioro de la salud mental, comportamientos de procrastinación, uso inapropiado de internet, entre otros fenómenos, no solamente ponen en riesgo el logro de resultados académicos positivos, sino que también pueden afectar el bienestar biopsicosocial y la integridad de los y las estudiantes.

\section{¿Cómo aprovechar esta experiencia?}

Como punto de partida, puede ser valioso reconocer los conocimientos, habilidades y estrategias adquiridas que no existían previamente, pero que se desarrollaron a partir de la 
pandemia, como, por ejemplo, el dominio de diversas plataformas virtuales. Seguramente una gran cantidad de personas desconocía la gran diversidad de plataformas útiles para llevar a cabo una clase o facilitar la adquisición de conocimientos. Posiblemente hay quienes aún tienen conocimientos mínimos (o nulos) para su manejo, pero a lo largo del tiempo se producirá una expansión del repertorio de mecanismos tecnológicos que podrán contribuir al desarrollo de habilidades digitales para la vida (personal y profesional).

Por otro lado, de acuerdo con la Organización de las Naciones Unidas para la Educación, la Ciencia y la Cultura (Unesco), las TIC tienen el potencial de mejorar las condiciones económicas, comunicativas y científicas de las poblaciones, principalmente las vulnerables y en condiciones de desigualdad (Unesco, 2019). Entonces, si consideramos la creciente importancia que se le ha dado al uso de las TIC para la resolución de las necesidades educativas emergentes, podría ser un excelente momento para impulsar la alfabetización digital, así como el fortalecimiento de la infraestructura necesaria para facilitar el acceso universal a este tipo de herramientas y, en consecuencia, impactar más allá del ámbito educativo.

De igual forma, es una oportunidad para fomentar habilidades socioemocionales y nuevos patrones de comunicación que permitan mejorar las interacciones dentro y fuera de los ambientes virtuales de aprendizaje. Por ejemplo, fomentar la comunicación asertiva y las estrategias de autorregulación emocional puede ser útil tanto para la ejecución de actividades académicas, como para mejorar los vínculos dentro del contexto familiar, lo que a su vez favorecería la consolidación de entornos libres de violencia.

Este tipo de habilidades socioemocionales permitirá un mejor ajuste social, así como relaciones más satisfactorias (Instituto Mexicano de la Juventud, 2018), aun después de la contingencia. Los/as profesionales de la salud mental deberían aprovechar la evidencia generada hasta el momento, para adecuar y proponer planes de acción para la prevención y atención oportuna de dificultades psicosociales características de las crisis sanitarias, a través del contexto educativo, y velar por su permanencia pospandemia, de tal manera que se conviertan en prácticas cotidianas con un mayor alcance del que se tiene actualmente. 


\section{Consideraciones finales}

La pandemia por COVID-19 ha generado una gran cantidad de problemáticas en el ámbito educativo internacional. La eventual crisis de los sistemas educativos desembocará en retrocesos significativos en la formación estudiantil, especialmente en las poblaciones más vulnerables, debido a las brechas que impiden dar continuidad a los programas formativos a distancia. Esto es especialmente importante cuando hablamos de clases a través de plataformas tecnológicas que dependen del acceso a internet. El hecho de que hayan docentes, cuidadores y/o estudiantes que habitan en zonas sin conectividad y/o que carecen de dominio de las plataformas en línea, pone en riesgo inminente el proceso enseñanzaaprendizaje.

Nos encontramos de cara a un reto educativo que, además, impactará en la capacidad de las naciones para el crecimiento socioeconómico y, consecuentemente, les dificultará salir de condiciones de pobreza y pobreza extrema (ONU, 2020d), como es el caso de los países de Latinoamérica. Es por esto que las acciones deben ser innovadoras, según la infraestructura tecnológica disponible en cada región, y basadas en principios de equidad y coordinación multisectorial, para que realmente se configuren como soluciones capaces de evitar la deserción escolar y garantizar el acceso universal a la educación de calidad (ONU, 2020d).

Por otro lado, es importante que de manera simultánea se impulse, en mayor medida, la introducción de actividades orientadas a proteger la salud mental de los diversos actores involucrados en el proceso formativo a distancia. Será necesario diseñar y evaluar la eficacia de programas y estrategias que permitan promover ambientes que normalicen los cambios conductuales y emocionales esperados ("normales"), pero lo suficientemente sensibles para identificar y canalizar a aquellas personas que presenten alteraciones con el potencial de poner en riesgo el afrontamiento efectivo de los retos asociados a la pandemia y el nuevo proceso enseñanza-aprendizaje.

Finalmente, es importante hacer hincapié en que, si bien es imprescindible adoptar una postura crítica respecto a las debilidades y áreas de oportunidad emergentes en esta nueva realidad, para modificar prácticas asociadas al rezago de los sistemas educativos, también es 
fundamental que todas las personas, organizaciones e instituciones del ámbito educativo adoptemos una actitud de apertura y resiliencia. Ello nos permitirá identificar las ventajas que ofrece la actual situación, aprovechar el aprendizaje, la experiencia y fortalecer nuestras capacidades de respuesta ante situaciones similares futuras, de manera individual y colectiva.

\section{Referencias}

Azamar, A. (2016). La integración de la tecnología al sistema educativo mexicano: sin plan ni rumbo. REencuentro. Análisis de Problemas Universitarios, 72, 11-25. https://www.redalyc.org/pdf/340/34051292002.pdf

Comisión Nacional de los Derechos Humanos. (2020). Entornos Familiares durante la cuarentena por COVID-19. https://www.cndh.org.mx/sites/default/files/documentos/2020-04/EntornosFamiliares-Sanos-Area-Medica-Psicologica.pdf

Instituto Mexicano de la Juventud. (2018). La importancia de las habilidades sociales en la población joven. https://www.gob.mx/imjuve/articulos/la-importancia-de-lashabilidades-sociales-en-la-poblacion-joven

Instituto Nacional de la Evaluación de la Educación. (2018). Gaceta de la Política Nacional de Evaluación Educativa 4(12), 3-5. https://www.inee.edu.mx/wpcontent/uploads/2019/01/G12_ESP.pdf

Instituto Nacional de la Evaluación de la Educación. (2019). La educación obligatoria en México. Informe 2019. https://www.inee.edu.mx/medios/informe2019/stage_02/index.html 
Instituto Nacional de Estadística y Geografía. (17 de febrero de 2020). En México hay 80.6 millones de usuarios de internet y 86.5 millones de usuarios de teléfonos celulares: Instituto Federal de Comunicaciones. http://www.ift.org.mx/comunicacion-ymedios/comunicados-ift/es/en-mexico-hay-806-millones-de-usuarios-de-internet-y865-millones-de-usuarios-de-telefonos-celulares

Kriscautzky, M. y Rodríguez, M. (2018). Investigación documental sobre el uso de TIC en la educación superior en Uso de Tecnologías de Información y Comunicación en la Educación Superior de México. Universidad Nacional Autónoma de México. https://educatic.unam.mx/publicaciones/estudio-uso-tic-educacion-superiormexico.pdf

Malander, N. M. (2016). Percepción de prácticas parentales y estrategias de aprendizaje en estudiantes secundarios. Revista de Psicología, 25(1), 1-19.

Mateo, M. (14 de abril de 2020). \#habilidades21 en tiempos de COVID-19. Enfoque Educación BID. https://blogs.iadb.org/educacion/es/habilidades21/

Organización de las Naciones Unidas. (04 de agosto de 2020a). El impacto del COVID-19 en la educación podría desperdiciar un gran potencial humano y revertir décadas de progreso. https://news.un.org/es/story/2020/08/1478302

Organización de las Naciones Unidas. (2020b). Covid, escuelas, México... Las noticias del martes. https://news.un.org/es/story/2020/08/1478322

Organización de las Naciones Unidas. (2020c). Más de 156 millones de estudiantes están fuera de la escuela en América Latina debido al coronavirus. https://news.un.org/es/story/2020/08/1478322

Organización de las Naciones Unidas. (2020d). Objetivo 4: Garantizar una educación inclusiva, equitativa y de calidad y promover oportunidades de aprendizaje durante toda la vida para todos. https://www.un.org/sustainabledevelopment/es/education/ 
Organización Panamericana de la Salud y Fondo de las Naciones Unidas para la Infancia (2020). Orientación para familias sobre autorregulación emocional y alternativas para la violencia en la crianza. https://www.unicef.org/lac/sites/unicef.org.lac/files/2020-07/AutorreguacionEmocional-Famiias-Prevencion-Violencia.pdf

Romagnoli, C. y Cortese, I. (2016). ¿Cómo la familia influye en el aprendizaje y rendimiento escolar? Valoras UC. http://valoras.uc.cl/images/centrorecursos/familias/ApoyoAlAprendizajeEnLaComunidad/Fichas/Como-la-familiainfluye-en-el-aprendizaje-y-rendimiento.pdf

Fondo de las Naciones Unidas para la Infancia. (2020a). El nuevo coronavirus y el derecho a la educación. https://www.unicef.es/educa/blog/nuevo-coronavirus-derechoeducacion

Fondo de las Naciones Unidas para la Infancia. (2020b). La falta de igualdad en el acceso a la educación a distancia en el contexto de la COVID-19 podría agravar la crisis mundial del aprendizaje. https://www.unicef.org/es/comunicados-prensa/faltaigualdad-acceso-educacion-distancia-podria-agravar-crisis-aprendizaje

Fondo de las Naciones Unidas para la Infancia. (2020c). La brecha digital impacta en la educación. https://www.unicef.es/educa/blog/covid-19-brecha-educativa

Fondo de las Naciones Unidas para la Infancia. (2020d). Orientaciones para docentes y recursos digitales para atender a la diversidad en la educación a distancia en el contexto del COVID-19. https://www.unicef.org/peru/sites/unicef.org.peru/files/202005/Orientaciones\%20\%26\%20recursos_MasInclusion\%2029.04.pdf

Fondo de las Naciones Unidas para la Infancia. (2020e). Apoyo emocional para niños y niñas ante el Covid-19. https://www.unicef.org/mexico/media/3161/file/Consejos\%20de\%20salud\%20ment al\%20para\%20ni\%C3\%B1as\%20y\%20ni\%C3\%B1os.pdf 
Villasana, N. y Dorrego, E. (2007). Habilidades sociales en entornos virtuales de trabajo colaborativo. Revista Iberoamericana de Educación a Distancia, 10(2), 45-74. 